CONFERENCIA

\title{
ARISTÓTELES, LA JUSTICIA POLÍTICA Y LA DEMOCRACIA DELIBERATIVA*
}

\author{
Óscar Godoy Arcaya
}

\begin{abstract}
El autor expone el trabajo analítico que le sirvió de base para dos conferencias dictadas el 29 de junio y el 6 de julio de 2005, en el contexto del ciclo “Aristóteles, filósofo para este tiempo", organizado por el Centro de Estudios Públicos (CEP). Aristóteles, según el autor, toma como punto de partida de su teoría política una doble genealogía de la ciudad (pólis): la naturaleza y la obra del legislador. Desde esa premisa, Aristóteles homologa la justicia política y la constitución, entendida como la organización de la ciudad. De esa homologación fluye una argumentación que pretende demostrar que los principios básicos de la constitución son el criterio fundamental para adjudicar, entre los ciudadanos, el poder político. Un poder que los ciudadanos van a ejercer como participación en los procesos de deliberación y decisión de la democracia. En este campo, el autor analiza la concepción aristotélica sobre la co-deliberación y el discurso retórico que le sirve de canal de expresión.
\end{abstract}

Óscar Godoy. Ph. D. Universidad Complutense de Madrid. Profesor titular de Teoría Política en el Instituto de Ciencia Política de la Universidad Católica de Chile. Miembro de número de la Academia de Ciencias Sociales, Políticas y Morales del Instituto de Chile. Consejero del Centro de Estudios Públicos.

* Véanse también en esta edición las conferencias de Alfonso Gómez-Lobo, “Aristóteles y una Disputa de Bioética”, y de Alejandro Vigo, “¿Está Obsoleta la Física de Aristóteles?”, dictadas durante el ciclo “Aristóteles, filósofo para este tiempo”, organizado por el Centro de Estudios Públicos el año 2005. (N. del E.) 
I este trabajo me hago cargo de dos temas que traté en el ciclo “Aristóteles, filósofo para este tiempo”, realizado en el Centro de Estudios Públicos, el pasado mes de julio del año 2005. Durante ese ciclo, abordé una serie de tópicos, entre los cuales destaco las teorías de Aristóteles sobre la felicidad y la virtud y sus concepciones de la ciudad, el ciudadano, la justicia política y la democracia deliberativa. Dado el carácter coloquial de esas conferencias, los temas fueron expuestos en forma sintética, bajo la presión de la brevedad del tiempo y el propósito práctico de incentivar la reflexión y el diálogo en la audiencia. Pero, como es habitual en este tipo de actividad, siempre hay una investigación analítica que le sirve de base. En este texto, redactado con posterioridad a las charlas, doy cuenta de ese trasfondo analítico desde el cual, durante el ciclo ya mencionado, construí mi exposición sobre la justicia política y la democracia deliberativa. La exposición está estructurada en dos partes. En la primera se aborda la cuestión de la justicia política y su relación con la constitución (politeia) y el modo de vida político (bíos polítikós) propio de la democracia. La segunda parte está dedicada a la democracia deliberativa, y, en consecuencia, sus hitos argumentales son la deliberación política democrática y el discurso deliberativo, tal como es concebido por Aristóteles en su obra la Retórica.

\section{Aristóteles y la justicia política}

El tema de la justicia política se inscribe en la concepción aristotélica de la pólis. De hecho su tratado la Política dedica los dos primeros capítulos de su primer libro a la teoría sobre la ciudad como la comunidad dotada de auto-suficiencia para la felicidad (eudaimonía). En este horizonte, el tratado mencionado vincula la estructura básica de la ciudad con la justicia política. Por esta razón es necesario empezar esta exposición haciendo un esbozo sobre la idea aristotélica de la ciudad.

\section{Doble genealogía de la ciudad aristotélica}

La ciudad aristotélica, en su concreción histórica, es la obra conjunta de la naturaleza y del legislador. Sabemos que Aristóteles nos ofrece argumentos convincentes y perdurables para afirmar que la ciudad (pólis) es una de las “cosas naturales” (tà physiká) que existen en la realidad. Su punto de partida es la evidencia de la insuficiencia del ser humano individual para realizar sus propios fines sin el concurso de los demás. Nos nece- 
sitamos mutuamente para la reproducción, el afecto conyugal y filial, la satisfacción de las necesidades cotidianas y no cotidianas y, en fin, para ser felices. Todos esos fines (téloi) están presentes en el individuo, considerado como un ser viviente racional, bajo la forma de impulsos (hormai) a transmitir la vida, al desarrollo afectivo, al cuidado de la prole, a la comunidad vecinal y a la comunidad política, a relacionarnos con el otro en distintas esferas de suficiencia, en suma, que cubren el amplio repertorio de lo que Aristóteles denomina las “cosas humanas” (tà anthropóonima) ${ }^{1}$.

Para una interpretación sintética de la argumentación aristotélica subyacente en su discurso sobre lo político, hay que poner el énfasis en tres ideas centrales, que aparecen en la Política ${ }^{2}$ : impulso (hormé), suficiencia o auto-suficiencia (autarkeía) y naturaleza (phýsis). El concepto de "impulso" (hormé) se refiere a la existencia en cada ser humano de los “primeros comienzos” o conatos de movimientos anímicos y corporales que apuntan o están dirigidos a la realización de ciertos fines (téloi). Estos impulsos emanan de todo aquello que contiene en sí mismo el principio de su existencia y su movimiento ${ }^{3}$. A esto, Aristóteles llama “naturaleza” (phýsis). De este modo, se puede decir que la naturaleza orienta a los seres humanos, en su desarrollo, a realizar fines, pues la "naturaleza es fin"4. Y que esa orientación incluye la constitución de esferas de suficiencia (autarkeía), sin las cuales el ser humano individual no podría culminar muchos de esos fines, impidiéndole el cultivo y la realización plena de sí mismo. Por esta razón, la ciudad, o sea el Estado, es definido por Aristóteles como una comunidad con plena suficiencia (autarkeía) para realizar el bien vivir (eu zçn) o felicidad (eudaimonía) ${ }^{5}$.

Los textos aristotélicos que han llegado hasta nosotros son muy generosos para exponernos los argumentos sobre la índole "natural” de la ciudad. Pero obviamente el filósofo no pensaba que el Estado era un producto de la naturaleza, como un hombre, un elefante o una manzana. En efecto, su teoría sobre la constitución de la ciudad establece con claridad, aunque con parquedad, que el legislador (nomothétes) es el agente que instala a la ciudad en la realidad. La ciudad es, de acuerdo al Estagirita, "según la naturaleza” (katà phýsin) porque ella se origina en una disposición estructural del ser humano a la vida política, pero también es una construcción de la racionalidad humana, capaz de concebir su forma (régi-

\footnotetext{
${ }^{1}$ Eth. Nic., 1181 b 15.

${ }^{2}$ Pol., I, capítulos 1 y 2.

${ }^{3}$ Phys., 192 b 13-14.

4 Pol., 1252 b 23.

${ }^{5}$ Pol., 1252 b 28 (29)-b 30.
} 
men político o politeia) y construirla efectivamente, tal como lo hace el nomothétes, el legislador fundador. Éste es, digámoslo al paso, justamente el asunto que trata la ciencia política (epistéme politiké), a la que Aristóteles definió como un saber legislativo del cual fluyen los vómoi, las leyes de la ciudad; en breve, una "nomotética”6. Así, en la Política, Aristóteles declara: "es natural (phýsei) la tendencia (hormé) a una comunidad tal (la pólis), pero el primero que la estableció fue causa de los mayores bienes” (megistoon agathoon aitios) $^{7}$.

El argumento de la eminencia del legislador se inscribe en la concepción aristotélica del hombre (ánthrôpos), como un "animal político” (zôn politikón), una especie superior de animal sustentado en el hecho que es el único “animal que tiene la palabra” (zôn lótgon éjon) ${ }^{8}$. En el texto pertinente, se entiende que el lógos es la palabra articulada que permite la comunicación entre los hombres, para expresarse mutuamente la relación de reciprocidad y cooperación que debe existir entre ellos. En efecto, el ser humano, según el filósofo, posee la facultad de “mostrar” lo útil (sýmphéron) y lo dañoso (blaberón), lo justo (tò díkaion) y lo injusto (tò ádikon) ${ }^{9}$, etc., o sea todo aquello que el lenguaje significa acerca de la relación de los individuos entre sí, y que, por lo mismo, hacen patente la necesidad de la ciudad.

Sobre la premisa recién expuesta, Aristóteles despliega la idea de que la magnitud de la obra del legislador brota de la absoluta necesidad de cimentar la cuidad sobre la justicia política (diké politiké). En efecto, a continuación del texto citado más arriba, el filósofo agrega un breve pero contundente argumento sobre esta cuestión. Este argumento, por su extrema concisión, es de difícil interpretación. Textualmente, dice así: (el legislador) “... fue causa de los mayores bienes, porque así como el hombre perfecto es el mejor de los animales, apartado de la ley y de la justicia (vómou kaì díkes) es el peor de todos: la peor injusticia es la que tiene armas, y el hombre está naturalmente dotado de armas para servir a la prudencia y la virtud (phrónesei kaì areté), pero puede usarlas para las cosas más opuestas. Por eso, sin virtud (aneu areté) es el más impío y salvaje de los animales, el más lascivo y el más glotón. La virtud de la justicia, en cambio, es cosa de la ciudad (dikaiosýne politikón), ya que la justicia política (diké politiké) es el orden de la comunidad civil, y consiste en el discernimiento de lo que es justo" (tou dikaiou krísis) ${ }^{10}$.

\footnotetext{
${ }^{6}$ Eth. Nic., 1181 b 12-15.

${ }^{7}$ Pol., 1253 a 30-31.

${ }^{8}$ Pol., 1253 a 5-10.

${ }^{9}$ Pol. 1253 a 15.

${ }^{10}$ Pol., 1253 a 30-38.
} 


\section{www.cepchile.cl}

Hay que destacar, por una parte, que la dikaiosýne es la "virtud de la justicia” y, por otra, que la diké es la justicia considerada en sí misma. Pero, además, hay que llamar la atención sobre la especificación que se les da a ambas en el texto, ellas son "políticas". No se trata solamente de la "virtud de la justicia” ejercida individualmente, que es objeto de la ética, sino de la "virtud de la justicia política", que cae en el campo de la ciencia política (epistéme politiké) entendida como nomotética. Y lo mismo ocurre con la justicia (diké), que no es considerada en este texto bajo una perspectiva filosófica o ética, sino en tanto es la justicia de la pólis considerada como un todo (hólon), la justicia política. Se trata, entonces, de que el ser humano, en su relación con el otro, o sea, en el seno de una comunidad, debe politizar su "sentido individual de la justicia” para actualizar la posibilidad de que todos los miembros de la comunidad cooperen entre sí en términos justos en las tareas del bien común. Este "sentido de la justicia” llevado a su perfección constituye para Aristóteles una virtud (areté).

Desde el punto de vista ético, el hombre perfecto (téleion) es aquel que logra la plenitud de su estatuto humano con la práctica de la virtud. Pero, desde la perspectiva de la ciencia política, ese hombre perfecto es substituido por la comunidad organizada, que utiliza las armas (hópla) de que están dotados sus miembros para alcanzar el bien común, bajo la guía de la justicia y la prudencia política. En esta esfera, distinta de la individual, la justicia política, establecida por el legislador, al fijar ese nómos fundamental de la ciudad, que es su constitución, dibuja la carta de navegación de la prudencia y la virtud políticas. Sin estos principios de la justicia política, contenidos en la politeia, los miembros-partes de la ciudad carecerían de ese último referente, regulador de sus actos, que les permite el ejercicio de la prudencia y la virtud de la justicia. Por esta razón, la obra del legislador es el mayor bien que alguien puede aportar a la comunidad.

Para concluir este parágrafo, recordemos que la obra del legislador se despliega a partir de la naturaleza. Según Aristóteles la ciudad es “por naturaleza” (katà phýsin) y, en consecuencia, “anterior” a los individuos. Esa anterioridad es estructural: cada ser humano tiende espontáneamente a reunirse con otros miembros de su especie para constituir una comunidad autosuficiente para el bien-vivir o felicidad. Pero, a la vez, la ciudad en su aparición y acontecer histórico es la obra del legislador (nomothétes). Tal es la doble genealogía de la ciudad aristotélica.

Politeia $y$ diké politiké

Aristóteles define a la justicia política como “el orden de la comunidad política (diké politikés koinonías táxis estín) y consiste en el discerni- 
miento de lo que es justo" (tou dikaiou krísis) ${ }^{11}$. Hay que destacar que esta definición es casi idéntica a la que Aristóteles atribuye a la politeia, o sea, a la constitución. Analicemos este punto. Aristóteles, en el libro III de la Política nos dice que la ciudad es una comunidad (koinonía) especial, "es decir, una comunidad de ciudadanos en forma de constitución” (estí de koinonía politon politeias $\left.{ }^{12}\right)^{13}$. Una formulación aristotélica más enérgica para expresar esta idea es la siguiente: "la comunidad es la constitución" (koinonía d'estin he politeia) ${ }^{14}$. Ahora bien, ¿qué es la constitución? Y el filósofo nos entrega la siguiente definición: "la constitución es el orden de los poderes en las ciudades (politeia men ghar ésti táxis tais polesin he perí tás arjás)”"15, o sea es el orden u organización de la ciudad o comunidad política. Ese ordenamiento (táxis), según la continuación de este texto, se refiere a cómo esos poderes (arjai) se "distribuyen y cuál debe ser en la ciudad el poder soberano (kyrion), así como el fin (télos) de cada comunidad"16. En consecuencia, como se desprende de la argumentación aristotélica, la justicia política y la constitución se identifican. Así, cada vez que el legislador fundador de la ciudad diseña e instala su constitución, lo que hace es establecer los principios por los cuales se distribuye el poder, se define la potencia última o soberana de la ciudad y, por último, se fija el fin de la misma. Y, como los criterios de distribución del poder entrañan la “adjudicación” de aquello que le corresponde a cada ciudadano, a cada institución y al poder soberano en general, es claro que la constitución se identifica con la justicia política propia de cada régimen. De este modo, si la constitución establece una democracia, al definir el fin (télos) de tal comunidad, necesariamente los principios de justicia política serán democráticos. Y así respecto de otros regímenes.

Si nos situamos en la perspectiva de los individuos que componen la ciudad, la justicia política les procura los criterios fundamentales que les permiten "discernir lo justo"17. Ya dijimos más atrás que este discernimiento se ejerce a partir del sentido de la justicia que existe como inclinación en los hombres, equivalente a uno de los poderes morales básicos que Rawls le

${ }^{11}$ Pol., 1253 a 30-38.

12 Aristóteles hace equivalentes los conceptos de constitución (politeñia) y gobierno (politeuma). Ver Política, 1279 a 26: los términos constitución y gobierno tienen la misma significación. Por esta razón es válida la traducción que dice “ciudadanos en forma de gobierno".

\footnotetext{
${ }^{13}$ Pol., 1276 b 1-4.

${ }^{14}$ Pol., 1276 b 30.

${ }^{15}$ Pol., 1289 a 15.

${ }^{16}$ Pol., 1289 a 16-18.

${ }^{17}$ Pol., 1253 a 39.
} 
atribuye a la persona ${ }^{18}$. Pero, además, este impulso natural puede ejercerse, según el Estagirita, en su nivel más alto de perfección, como "virtud de la justicia” (dikaiosune). Recordemos, una vez más, que la virtud (areté), para los griegos, es la perfección de una disposición natural, que resulta de un cultivo de sí mismo, ejercido en vistas a la adquisición de un éthos, un carácter. Ahora bien, la virtud política involucra a la comunidad. Es la virtud de la justicia "en" y "de" la ciudad. Y, como ya se estableció, no puede darse sino como un fenómeno ciudadano. Por lo tanto, el sujeto de esta virtud es la ciudad misma como un todo (hólon) y los ciudadanos como partes de ella. Y ya veremos, más adelante, cómo Aristóteles resuelve este dilema de atribuirle "virtud" a una comunidad, siendo así que parece ser solamente un atributo adquirido por los individuos.

Por el momento, lo importante es tener presente que el bíos polítikós democrático, fundado en una constitución y su justicia política, parte del supuesto de que el télos de la ciudad es la felicidad. Ahora bien, Aristóteles nos dice que para la consecución de ese fin final (télos téleion), la ciudad debe crear un orden (táxis) y las condiciones necesarias para que los individuos puedan alcanzar el bien vivir. Un orden que debe darle una estructura básica a una comunidad de hombres libres e iguales y cuyas instituciones permitan su participación activa y directa en los asuntos de la pólis. Un orden que, además, debe asegurar la suficiencia (autarkeía) de las distintas esferas asociativas de las personas, para que satisfagan plenamente sus fines naturales y artificiales. O sea, todos aquellos elementos que integran y hacen real un verdadero bíos polítikos democrático. De todo esto se ocupa la constitución, que en definitiva permite que los individuos reconozcan, en sus relaciones con el otro, aquello que le corresponde o le es debido a cada cual, como algo suyo: o sea, el punto de partida, moral y político, de una vida común justa que cruza las generaciones.

Ahora bien, para proseguir la argumentación en curso, fijemos nuestra atención en un concepto central de la definición de constitución expuesta más arriba. Cuando esa fórmula nos dice que el establecimiento de un orden (táxis) consiste en la "distribución” de los poderes (arjai), inequívocamente se nos remite a los principios de adjudicación de los mismos. De algún modo la politeia, o sea la justicia política, debe establecer cómo se distribuye o adjudica el poder. Por esta razón, la justicia política es justicia distributiva o justicia de la adjudicación. Sobre este supuesto, ahora podemos responder a la pregunta por la concepción que Aristóteles tiene sobre la justicia política democrática. O sea, por la justicia que establece la adjudicación de poderes propia de la democracia.

${ }^{18}$ Rawls, John: Political Liberalism (1993); pp. 19-20; 302. 
La constitución o justicia política democrática

El orden (táxis) al cual Aristóteles se refiere es la proyección de la justicia distributiva adoptada por el legislador fundador para cada constitución. De acuerdo a Aristóteles, toda ciudad distribuye la autoridad o el poder político en conformidad con algún criterio o principio de adjudicación. Ese principio es siempre un atributo o cualidad de la persona humana -interno o externo- que la politeia reconoce como la axía o valor último que se aplica en la adjudicación del poder ${ }^{19}$. Aristóteles, a este respecto, nos propone cuatro alternativas: la libertad (eleuthería), la riqueza (ploutón), el linaje (eugéneian) y la virtud (areté) ${ }^{20}$. Así, cada una de estas axiai (valores) está a la base de la constitución y la justicia política de la democracia, la oligarquía (riqueza y linaje) y la aristocracia respectivamente.

Aristóteles, tanto en la Ética Nicomaquea como en la Eudenia, desarrolla su teoría de la justicia política, entendida como justicia de la adjudicación o distribución, recurriendo a la proporcionalidad geométrica (analogía geometriké), que es una igualdad de cuatro términos agrupados en dos ratios (isotes logon). En la justicia distributiva, los cuatro términos son los siguientes: dos personas, por un lado, y dos participaciones de poder político, por otro ${ }^{21}$. Así podemos establecer una analogía de proporcionalidad que dice que Calias es a Sócrates, como " $\mathrm{x}$ " poder político es a "y" poder político. Pero, para atribuir "x" e "y" de un modo concreto necesariamente debemos establecer el atributo, cualidad o valor (axía) de Calias y de Sócrates que los hacen acreedores o dignos de que se les adjudique tales proporciones de poder. Y lo que establece la constitución democrática, como ya vimos, es que ese atributo o "valor-dignidad" (axía) es la libertad (eleuthería). Entonces, dado que tanto Calias como Sócrates son "igualmente" hombres libres (eleutheroi), les corresponde una participación proporcional de poder político. Si la axía es la riqueza, en lugar de la libertad, como es el caso en el régimen oligárquico, la adjudicación de "x" e "y" establecerá que a cada persona se le asignarán cuotas de poder en proporción a su desigual posesión de riqueza.

Si en n la justicia distributiva democrática aristotélica, aquello que habilita a las personas como sujetos beneficiarios de la adjudicación de poder o autoridad es su libertad, surge la pregunta, ¿qué es la libertad?, ¿en qué consiste ese atributo humano encapsulado en el término "ser libre"? Una de las respuestas aristotélicas toma como punto de partida la figura del

\footnotetext{
${ }^{19}$ Eth. Nic., 1181 a $25-29$.

${ }^{20}$ Eth. Nic., 3, 1181 a 28-29.

${ }^{21}$ Eth. Nic., 1181 a 30.
} 
esclavo. Ser esclavo es no ser dueño de sí mismo. Por el contrario ser libre es ser dueño de sí mismo ${ }^{22}$. Y, más allá del significado jurídico, que tal fórmula incluye, ser dueño de sí mismo en sentido moral es la auto-posesión, o sea el gobierno autónomo de sí mismo por la razón, por el lógos. En un régimen democrático la primera adjudicación de poder que se le dispensa a un hombre libre es su investidura como ciudadano (polítes). La ciudadanía transforma a los hombres libres en portadores o sujetos de derechos políticos, que se van a ejercer participando en las instituciones de la pólis.

En su estudio de la ciudadanía, el Estagirita nos va a procurar otras características del hombre libre, sin las cuales no se le podría atribuir esa calidad. Entre ellas, hay que poner en primer lugar la oposición entre el nativo y el extranjero. De este modo, es libre aquel que es dueño de sí y, además, nativo (y no extranjero) del país gobernado por la constitución de que se trate. Un tercer elemento es el parentesco, en el sentido que la persona libre debe proceder de padres o ancestros libres (en distinto grado y mezcla $)^{23}$. Por último, hay que agregar el sexo y la edad. Solamente pueden ser ciudadanos los varones libres, y, más específicamente, los hombres jóvenes y maduros. Quedan excluidos, entonces, los ancianos. Así, las mujeres, los niños y los ancianos pertenecen a un estadio inferior de libertad, en el cual no opera la adjudicación de poder en virtud de la libertad. De hecho esta concepción de la libertad estuvo vigente en las ciudades-estados griegas en los siglos V y IV a. C.

Ahora bien, Aristóteles distingue entre los principios constitucionales y las instituciones a través de las cuales ellos se aplican. En el caso de la justicia democrática (tò demotikon dikaion), el mismo filósofo distingue entre el principio libertad y los medios o instrumentos para ponerlo en práctica, o sea las instituciones democráticas (tà demotiká) necesarias para realizarlo ${ }^{24}$. Estos demotiká se sustentan en dos axiomata o postulados de la democracia ${ }^{25}$ : el primero dice que "todos los ciudadanos deben estar en pie de igualdad"26; y el segundo, afirma que "cada cual viva como le agrade", como "un efecto de la libertad"27. En las demotiká que se enumeran más adelante, los ciudadanos participan en virtud de la adjudicación de poder político que hace justicia política. Aristóteles, en su obra la Constitución de Atenas hace una minuciosa enumeración y descripción de las demotiká

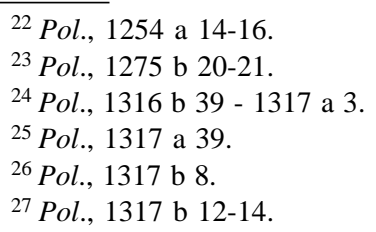


atenienses del siglo IV, de las cuales destacamos las siguientes: (1) la Asamblea o Ekklesía, a la cual pertenecen todos los ciudadanos. (2) La Boulé o Consejo (de los Quinientos o Cuatrocientos, según la época). (3) Los legisladores o nomothetai. (4) Los tribunales o cortes de justicia. (5) Los jurados, que hacen los escrutinios o evaluación (dokimasíai) del ejercicio de todos los cargos públicos de la ciudad. (5) El gobierno de la pólis, o sea, el órgano de la autoridad ejecutiva y administrativa de la ciudad. (6) Y, en fin, los mandos militares y navales, elegidos por elección mayoritaria.

La regla procedimental general para atribuir las funciones políticas a los individuos es el sorteo ${ }^{28}$, con la excepción de la Asamblea, a la cual pertenecen todos los ciudadanos, y los mandos militares, a los cuales se agregaba cierto tipo de judicatura especializada en el comercio exterior, que eran elegidos por decisión mayoritaria ${ }^{29}$. Además, con la excepción de la membresía permanente de la Asamblea, el resto de las posiciones de poder tenían un mandato breve de hasta un año. Ello generaba una gran alternancia. De este modo, junto con el procedimiento aleatorio del sorteo, esta alternancia garantizaba a los ciudadanos una vasta igualdad de oportunidades en el acceso al poder político.

De este modo, para Aristóteles, como se desprende de lo expuesto, el ciudadano es aquel que participa en las magistraturas de la ciudad ${ }^{30}$. Cada ciudadano tiene una igual libertad en distintas esferas de la vida política. Ahora bien, el bíos polítikós democrático se despliega con mayor intensidad en la Asamblea. Ella es el escenario público más perfecto para el ejercicio de la igualdad de la ley (isonomía), la igual libertad de palabra (isegoría) y la parrhesía o franquía para decir lo verdadero sin riesgo o censura $^{31}$. Los ciudadanos, provistos de estas libertades, cumplen con las funciones políticas más altas de la ciudad: legislar y actuar como tribunal de justicia. Y, en el resto de las instituciones, debido a la alternancia en el poder, que maximiza la igualdad de oportunidades ${ }^{32}$, se aplica una segunda definición de ciudadano, solamente válida en la democracia, que dice que éste es “aquel que alternativamente manda y obedece"33.

${ }^{28}$ Ath., 41-60.

${ }^{29}$ Ath., 61.

${ }^{30}$ Pol., 11275 a 22-24; 1275 b 19-21.

${ }^{31}$ Según Platón, en la carta VII, el tirano concede esta franquía, pero el beneficiado puede perder la vida o la libertad si la ejerce disgustándolo.

${ }^{32}$ La probabilidad de ser seleccionado para ocupar una función de autoridad política debería ser la misma para todos durante el transcurso de una vida completa. Esta regla se apoya en el ejercicio del sorteo como procedimiento aleatorio de selección.

${ }^{33}$ Pol., 1277 a 25-27. 


\section{Democracia deliberativa}

La Asamblea es el órgano soberano del régimen político democrático. A ella pertenece la totalidad de los ciudadanos, que son sus miembros permanentes. Para la realización de sus funciones legislativas y judiciales, los ciudadanos reunidos en la Ekkesía deliberan y deciden. Ahora bien, según Aristóteles, la deliberación (bouleusis) y la decisión o elección (proairesis) son actividades de la razón práctica aplicadas a la vida de la comunidad política. En efecto, la sabiduría práctica y política consiste justamente en deliberar y tomar buenas decisiones para el bien de la ciudad.

Pero antes de analizar esa doble actividad de la deliberación y la decisión colectiva es necesario saber si el pueblo es competente para orientar a la ciudad hacia su fin final, a través de la prudencia y la virtud, como lo hacen los individuos o los regímenes del príncipe virtuoso y de los mejores (aristoi). Y para ello Aristóteles argumenta a partir del fin (télos) de la ciudad. Como ya quedó establecido, el filósofo sostiene que ese fin es el bien vivir o felicidad. Por eso, Aristóteles vuelve sobre esta definición para enfrentar la cuestión de la competencia del pueblo para discernir el bien en la esfera de la ciudad: ese fin que orienta a la comunidad al bien vivir ( $e u$ zeen). Ya sabemos que el sabio (sofós) y los mejores (aristoi) están habilitados para esa tarea, pues su cualidad es justamente ser virtuosos. Pero ¿cómo podría atribuírsele al pueblo ese discernimiento propio del sabio y de los virtuosos?

La Asamblea está compuesta por el pueblo (démos), que no es la totalidad de la comunidad política, sino principalmente la mayoría (pléthos), que son los ciudadanos pobres, los áporoi, los “sin salida”, por una parte; y secundariamente por los ricos (euporoi), que constituyen la minoría (oligoi), por otra. En consecuencia, la pregunta sobre la competencia del pueblo para discernir el bien de la ciudad, cada vez que delibera y decide algún asunto público, en rigor es una pregunta sobre la competencia de la mayoría (pléthos), de los más (pol-loi), para tan elevada actividad. Y la respuesta de Aristóteles es sorprendente. "Podría ser, en efecto, que los más (pol-loi), aun cuando no sean individualmente hombres virtuosos (spoudaios aner), sean con todo mejores, cuando se asocian, que estos otros, no individual sino colectivamente” (sýmpantas) ${ }^{34}$. Aristóteles argumenta que entre los más, “cada uno tiene una parte de virtud y prudencia, y reunidos viene a ser la multitud como un solo hombre dotado de muchos pies y muchas manos y muchos sentidos”35. De este modo, Aristóteles despeja la cuestión de la

\footnotetext{
${ }^{34}$ Pol., 1281 b 1-2.

${ }^{35}$ Pol., 1281 b 4-7.
} 
competencia de la mayoría (pléthos), que operando como un colectivo está habilitada para establecer el bien de la ciudad. Se trata, para el filósofo, de un "principio verdadero", pero con un proviso: "no es cosa averiguada que esta superioridad de la mayoría sobre la minoría selecta pueda darse en todo pueblo y en toda mayoría (perí panta démon kái perí pan pléthos) ${ }^{36}$.

Establecida la eventual competencia de la mayoría para discernir el bien público, tal como lo haría idealmente el virtuoso, conviene ahora responder a la pregunta por aquello que abarca la esfera de la deliberación. En otras palabras, ¿acerca de qué podemos legítimamente deliberar? La respuesta a esta pregunta está desarrollada, en distintos niveles éticos y epistemológicos, en la Ética Nicomaquea. Por de pronto, para abordar este tema, vamos a centrarnos en la esfera de la realidad que, según Aristóteles, pertenece a las cosas deliberables. Para la comprensión sumaria de este punto hay que distinguir, siguiendo al filósofo, tres niveles de realidad: las cosas que acontecen "siempre" (aeî); las cosas que acontecen "las más de las veces” (hôs epí tò polú) y las que tanto pueden ser como no ser (tá endechomena álôs éjein) $)^{37}$. Las primeras son eternas, necesarias y universales y son objeto de la ciencia (epistéme). Sobre ellas hacemos teoría a través de nuestra razón pura o especulativa. Nadie “delibera” acerca de estas cosas; por ejemplo, sobre la ley de gravedad. Las "cosas que acontecen las más de las veces” son aquellas que ocurren según un régimen de regularidad, que admite excepciones que las aparta del "siempre” de las cosas necesarias. Se puede aducir como ejemplo al tiempo como objeto de la meteorología. Aquí tampoco hay campo para la deliberación, porque en este tipo de cosas no interviene nuestra voluntad (como tampoco en el caso anterior). Restan las cosas que pueden ser o no ser. O sea, las cosas contingentes, que pertenecen justamente al dominio propio de la deliberación. Aristóteles nos dice, en la Ética Nicomaquea, que podemos deliberar solamente acerca de todo aquello que podemos hacer por nosotros mismos ${ }^{38}$, en un tiempo por venir o futuro ${ }^{39}$, $\mathrm{y}$, como es patente, ellas corresponden a la categoría de las cosas contingentes.

Lo anterior tiene una segunda significación. La deliberación no es una actividad de la razón pura o especulativa, que "sólo piensa” (“el pensamiento por sí mismo nada mueve” ${ }^{40}$ ), como dice Aristóteles, sino de la razón práctica. En consecuencia, su objeto no es exacto ni autosuficiente, como lo

\footnotetext{
${ }^{36}$ Pol., 1281 b 16-22.

${ }^{37}$ Eth. Nic., 1134 a 30 - b 5.

${ }^{38}$ Eth. Nic., 1140 a 32-33.

${ }^{39}$ Eth. Nic., 1139 a 7-9.

${ }^{40}$ Eth. Nic., 1139 a 38.
} 
es el objeto del saber científico, por ejemplo aquel de las matemáticas o de la física. Quien delibera, dice Aristóteles, está comprometido en la búsqueda de una solución a un problema, que consiste en “cómo” actuar con vistas a la realización de un determinado fin en una coyuntura de cambio, propio de la contingencia política. En consecuencia, la deliberación se refiere a los medios más adecuados para alcanzar tal o cual fin. Para el filósofo, los principales fines a los cuales apunta la deliberación individual están dados por la naturaleza. Y aun cuando, por este hecho, se entiende que los fines son universales, el discernimiento racional de los medios, operado por la deliberación, trata siempre de lo particular. En este sentido, entonces, la actividad deliberativa se despliega en la esfera de la contingencia, de aquello que es particular ${ }^{41}$, y que, por lo mismo, carece del atributo de la exactitud propio del objeto de la ciencia.

No obstante, la deliberación política, por ser deliberación colectiva o co-deliberación, en cierta medida también delibera acerca de los fines. No delibera respecto de cada fin considerado en sí mismo. Por ejemplo, no se delibera si la comunidad política debe organizarse para los fines de la defensa, la salud, la educación, etc., sino sobre los medios de alcanzarlos. Pero, también se delibera sobre la jerarquización y priorización de esos fines, teniendo a la vista la escasez de los recursos y otros factores. Pero, para Aristóteles, ello no obsta a la anterioridad de los fines: ellos son pre-establecidos y de suyo realizables por la acción colectiva humana. La cuestión capital que enfrenta la deliberación es cómo realizarlos.

\section{La deliberación y su relación con la prudencia}

Pero surge un problema. Entre las cosas contingentes, que podemos "hacer por nosotros mismos", hay algunas que se producen por intermedio de un saber técnico. Las artes productivas se ocupan de este tipo de cosas. El arquitecto, por ejemplo, dispone de un saber técnico para producir la casa. Cuando el arquitecto aplica sus conocimientos para diseñar y producir la casa, ¿estará acaso deliberando? La respuesta de Aristóteles es negativa. Y el supuesto de su respuesta es epistemológico. Ya dijimos más atrás que la deliberación es una actividad de la razón práctica, o sea de aquella que regula nuestros actos y tiene el poder de ordenarlos hacia el bien. Lo que está en juego en la co-deliberación política es el discernimiento de los medios para alcanzar un cierto fin de la ciudad. Y, como es obvio, esos medios consisten en actos que deberán ser ejecutados por la comunidad. En efecto,

${ }^{41}$ Eth. Nic., 1141 b 15-16. 
una vez que culmina el proceso co-deliberativo, aquello últimamente deliberado se transforma en decisión. Y la decisión no es sino, en una democracia, aquello que queda establecido en la ley o bien aquello que ha de ejecutarse por el gobierno. Ahora bien, si la deliberación trata sobre los actos legislativos y ejecutivos, por un lado, y ella emana de hombres libres, con el título de ciudadanos, reunidos en Ekklesía, por otro, el proceso racional que la sustenta no puede confundirse con aquel de la producción ${ }^{42}$.

El proceso productivo, que los griego llaman poiesis, tiene por finalidad la puesta en la realidad de un producto (poema), externo al agente, como es la casa concebida y realizada por al arquitecto. La racionalización de ese proceso constituye el saber técnico que corresponda, según el producto que pretenda realizar. Y un técnico (technités) es aquel que posee y domina esa técnica o arte (téchne) y es capaz de aplicarla como un modo de producir $^{43}$. Para Aristóteles, la deliberación y la decisión no constituyen un saber de este tipo. La acción (praxis) humana que hace bueno (o malo) a un hombre tiene un efecto "interno" en el mismo sujeto que la ejecuta: lo hace bueno (o malo). Análogamente, la deliberación y la decisión política, que discierne y elige lo que debe hacer la comunidad, son actos colectivos cuyos efectos revierten sobre la comunidad misma, como sujeto de esa acción. Si la técnica ordena los actos necesarios para la producción de algo externo al agente, la deliberación y la decisión colectiva generan un "estado interno” (inherente) a la comunidad. La decisión de extinguir la pobreza, por tales o cuales medios, una vez ejecutada debe dar como resultado un nuevo “estado” de la sociedad, como una obra (érgon) de la comunidad sobre sí misma. El saber que se aplica en la deliberación no es ni una ciencia, ni una técnica, sino la prudencia (phrónesis). Éste es, digamos al paso, uno de los puntos de ruptura con Platón más radicales. Por esta razón, Aristóteles, como vimos, nos dice que el individuo sin ciudad (o fuera de la ciudad) no puede ejercer la prudencia ni tampoco la virtud. Y la prudencia, tal como aparece explicada en la Ética Nicomaquea, es un saber práctico, una virtud de virtudes, que en esencia involucra, en quien la detenta, poseer la capacidad permanente (hábito, héxis) de “deliberar rectamente”.

Aristóteles desarrolla su concepción de la prudencia (phrónesis) en el libro VI de la Ética Nicomaquea, en el contexto de su teoría sobre las virtudes intelectuales (ciencia, técnica, prudencia, intuición de los principios y sabiduría). Esa concepción se nos presenta a través del sujeto que la posee y practica, el prudente (phrónimos). A primera vista, el prudente se caracteriza por poseer el poder o capacidad (dunamis) de “deliberar acerta-

${ }^{42}$ Eth. Nic., 1140 a 13-20.

${ }^{43}$ Eth. Nic., 1140 b 5. 
damente acerca de las cosas buenas y provechosas para él, no parcialmente, como cuáles son buenas para la salud o el vigor corporal, sino cuáles lo son para el bien vivir en general” (pros tò eu zçn hólos) ${ }^{44}$. Aristóteles enfatiza que el bien que tiene a la vista el prudente no es relativo a una parte de la existencia de cada cual, sino al todo de la misma, es decir, a su felicidad como fin final. Esta visión holística del bien humano, como horizonte del prudente, se aplica a la prudencia política. Una vez más, en este caso, la Asamblea, o sea, los ciudadanos como un todo (hólon), va a deliberar y adoptar decisiones “prudenciales” con vistas a la realización no solamente de bienes parciales de la ciudad, sino de su bien finalísimo, que es el bien vivir o felicidad. De este modo, la preservación de la ciudad, sus riquezas, su comercio, su sistema de salud y de educación, su infraestructura física, su defensa, etc., como dimensiones particulares, se ordenan al bien vivir de la ciudad en general. El prudente, dotado de esta capacidad, “calcula” bien aquello que es conveniente o útil, y, en este sentido, dice Aristóteles, se lo puede definir como "aquel que sabe deliberar".

Ya sabemos que no hay deliberación sobre el objeto de la ciencia (epistéme), ni de la técnica (téchne). La deliberación trata acerca de lo contingente futuro (que podrá ser o no ser), realizable por nosotros mismos (por eso, dice el Estagirita, no deliberamos sobre los asuntos de la India). Aristóteles nos da el ejemplo de Pericles, como un phrónimos que sabía deliberar bien, diciéndonos que podía “percibir” las cosas buenas para él y los hombres. De individuos prudentes como Pericles, dice el filósofo, podemos decir que son capaces de "dirigir las familias y las ciudades”45.

Ahora bien, esa “percepción”, que ejerce el prudente, consiste en el "hábito práctico verdadero, con relación a los bienes humanos"46. Esta apretada fórmula abre distintos frentes. Por de pronto sitúa a la prudencia dentro de las virtudes intelectuales, puesto que es un hábito (héxis) que ordena a los actos según la verdad (alçetheia) iluminada por el lógos. Obviamente esta verdad no es una verdad especulativa, ni una verdad técnica, sino aquella de los fines de los "bienes humanos" (tà anthropóonima agatá) y de los actos (praxei) a través de los cuales (medios) ellos pueden realizarse. Por esta razón, el prudente no solamente delibera, sino que delibera "bien”. Aristóteles incluye en su conceptualización la figura del prudente como "buen consejero", o sea, como practicante de la euboulía, de la buena deliberación. El buen consejero (eubolos), en efecto, es aquel que “ajustándose a los cálculos de la razón, acierta con lo mejor de lo que puede

\footnotetext{
${ }^{44}$ Eth. Nic., 1140 a $27-29$.

${ }^{45}$ Eth. Nic., 1140 b 8-11.

${ }^{46}$ Eth. Nic., 1140 b 20-22.
} 
ser realizado por el hombre"47. Este cálculo de la razón participa de lo universal, porque tiene a la vista los fines; pero, a la vez, es un conocimiento de lo particular, porque se ordena a la acción, y ésta siempre se refiere a cosas particulares. El conocimiento de lo particular, por su parte, da pie a Aristóteles para establecer la relevancia de la experiencia (empeiría) en el saber prudencial y la deliberación. Tan importante es la experiencia que en este plano es superior al saber científico o técnico, porque sabe el "cómo" de los fenómenos particulares, aunque desconozca la causa. Y dado que la experiencia se adquiere con el "mucho tiempo", Aristóteles explica que los jóvenes, que pueden dominar a la perfección las matemáticas y la geometría, no saben ejercer la virtud intelectual de la prudencia ${ }^{48}$.

\section{Formas deliberativas y retórica}

Pero no se ha incluido en la argumentación al hombre libre, como miembro de la comunidad democrática, en forma gratuita. Pues, en efecto, esa condición de libertad sella una diferencia fundamental. Solamente el hombre libre está habilitado para hacer el discernimiento propio de una “elección deliberada”. Por el contrario, un hombre no libre, en estado de tutela, como diría Kant, o bajo la sujeción de otra voluntad, es un esclavo. Y un esclavo es incapaz de hacer la elección deliberada. La inferencia que nos dice que este principio se aplica a una comunidad de hombres libres, es decir a la pólis democrática, es perfectamente legítima. Ya sabemos que las instituciones democráticas son los instrumentos para la adjudicación de poder político a los ciudadanos. Esa adjudicación cobra la forma concreta de “miembros titulares" de la Asamblea, los legisladores, los jueces, los jurados, el gobierno, las fuerzas armadas, etc. También sabemos que "los más”, considerados como un todo (hólon), reúnen en sí mismos la prudencia y la virtud necesarias para la buena deliberación y decisión de los mejores medios para alcanzar el bien vivir de la ciudad.

Ahora bien, para darnos una idea final sobre la democracia deliberativa aristotélica, es necesario tocar dos temas adicionales, que completan nuestra argumentación general. El primero se refiere a las formas que asume la deliberación en la ciudad. Y el segundo, al tipo de discurso a través del cual los ciudadanos se comunican y discuten sobre los medios posibles para realizar el bien de la ciudad.

\footnotetext{
${ }^{47}$ Eth. Nic., 1141 b 14.

${ }^{48}$ Eth. Nic., 1142 a 13-15.
} 
Aristóteles, en el capítulo 8 del libro VI de la Ética Nicomaquea, dice que el saber político y la prudencia se fundan en la misma héxis, o modo constante del carácter (éthos); sin embargo, anota, ambos deben ser entendidos desde dos puntos de vista diferentes ${ }^{49}$. En efecto, la palabra phrónesis, prudencia, se aplica principalmente a la acción individual y por esta razón su estudio corresponde a la ética. En cambio, el saber político, al cual también podemos llamar “prudencia política”, está constituido por el mismo hábito (héxis), pero aplicado a los fines de la ciudad entendida como un todo (hólon). Ahora bien, este saber político se divide en dos esferas: una a la cual Aristóteles llama “prudencia legisladora” y otra que trata sobre los asuntos particulares. La primera se refiere a la obra del legislador fundador, o sea, al autor del nómos constitucional, según hemos visto; y la segunda a la actividad deliberativa sobre los medios particulares para realizar los fines instrumentales y el fin último de la ciudad. A esta última le corresponde en rigor la denominación de "prudencia política”. A la primera Aristóteles también la califica como “arquitectónica” (architektoniké), porque de ella fluye la ley suprema de la ciudad, la constitución, que ordena y da coherencia primaria a la estructura básica de la comunidad política. Y a la segunda Aristóteles le atribuye la emisión de “decretos", como expresión de "lo último que debe hacer el gobierno”. El contenido de esto "último” es la acción que, después de la deliberación, se ha elegido desplegar, como un medio para realizar algún fin de la ciudad. Y agrega, para hacer un contraste con la "prudencia legisladora", que los que gobiernan descienden a la "práctica”, "porque sólo ellos ejecutan acciones, como los operarios en una industria” (cheirotéchnai), o sea, como aquellos que trabajan con las manos, y no dirigen desde las alturas de un saber arquitectónico ${ }^{50}$. El descenso de los ciudadanos a la práctica, en la frontera de lo "último” y no de lo primero (los principios constitucionales), se realiza en las instituciones democráticas ejecutivas de gobierno y administración del Estado. Ya mencionamos los derechos y las instituciones de las cuales participan para poder legislar, juzgar, deliberar y decidir. Esta activa participación directa de los ciudadanos, especialmente en la Ekklesía, constituye el núcleo sustantivo de un bíos polítikós, un modo de vida político, al servicio del bien vivir, que se despliega en práctica y actos de gobernación.

La segunda cuestión final que deseamos abordar trata sobre las formas discursivas propias de las prácticas deliberativas. Estas formas se refieren a la estructura del razonamiento que, según Aristóteles, se despliega cuando se ejerce la deliberación política. Una vez más, recordemos que la deliberación no es objeto de una ciencia, ni de una técnica. Por lo tanto,

\footnotetext{
49 Pol., 1241 b 23-24.

${ }^{50}$ Eth. Nic., 1141 b 29-30.
} 
desde el punto de vista del discurso a través del cual ella discurre, la deliberación no argumenta siguiendo el modelo de la demostración apodíctica, tal como ella es explicada en el Organom ${ }^{51}$. O sea, no construye el discurso modelado por el silogismo propio de la ciencia, que concluye nuevas verdades fundado en premisas que contienen verdades ya conocidas, y cuya verdad se remonta, en última instancia, a principios verdaderos por sí mismos. Este modo argumental no tiene ninguna validez ni viabilidad en la Asamblea, ni en cualquier colectivo político que deba co-deliberar para escoger los medios más adecuados y eficaces para realizar algún fin ciudadano. En los Tópicos ${ }^{52}$, Aristóteles nos dice que en la discusión que se entabla "entre" y "ante" los po-loi, los más, se debe tomar como punto de partida el uso de nociones comunes. La Retórica justamente remite al texto recién citado para afirmar que en la situación descrita "es preciso que los argumentos y los razonamientos se hagan mediante nociones comunes"53. Más explícitamente, Aristóteles sostiene que los interlocutores de la deliberación, dada la naturaleza misma de esta actividad, que recae sobre "cosas que parecen admitir ser de dos maneras, no pueden inferir a través de muchos grados, ni razonar tomándolo desde lejos”. Esto quiere decir que no se delibera construyendo cadenas deductivas, como es propio del saber científico en el sentido aristotélico. Todas las ciencias operan haciendo inferencias, que se sostienen, en primera instancia, en una premisa fundacional, universal, necesaria y verdadera por sí misma. Es por eso que en el modo de razonar de la ciencia su fundamento viene “desde lejos”. En cambio, la deliberación trata sobre los medios particulares, y, en consecuencia, su campo propio es la contingencia, eso "último" o inmediato donde cumple su tarea la política.

El discurso deliberativo dispone de un arte o una técnica (téchne) para intermediar entre los ciudadanos reunidos. Esa técnica es la retórica, que, en palabras de Aristóteles, versa sobre "cosas que en cierto modo son de conocimiento común a todos y no corresponden a ninguna ciencia determinada" 54 . Como es evidente, el campo de la retórica es mucho más extenso que aquel de la deliberación política. En consecuencia, para establecer la relación entre ambos es necesario hacer algunas precisiones preliminares.

En primer término, hay que notar que el razonamiento retórico tiene la estructura material básica de todo razonamiento, es decir, está compuesto

\footnotetext{
${ }^{51}$ En los Segundos Analíticos del Organon se desarrolla la teoría de la demostración.

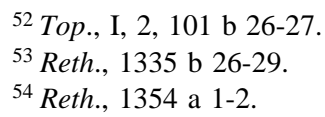


por silogismos. Y, como todo razonamiento, en un sentido muy general, también tiene el propósito de demostrar algo. O sea, pasar de algo ya conocido a un nuevo conocimiento. Por el hecho de que su objeto sea tan indeterminado, que no pueda corresponder a una ciencia ocuparse de él, surge la pregunta: ¿qué es lo que “demuestra” el razonamiento retórico? Esta pregunta es válida, aunque en rigor este tipo de razonamiento constituye solamente una “especie de demostración”. En términos generales, toda demostración no hace sino "acreditar” la validez de algo. En el razonamiento científico, la deducción demostrativa acredita la verdad de un teorema o de un axioma de la geometría, por ejemplo.

¿Qué es lo que acredita el razonamiento retórico? Aristóteles nos dice que la demostración retórica es un “entimema” y que éste, a su vez, es un silogismo. O sea, según contabilizamos en este texto, nos encontramos con dos especies de silogismos, el científico y el retórico (entimema). Ya tenemos claro que el científico demuestra o concluye en una nueva verdad (filosófica, física, matemática, geométrica, astronómica, etc.). Ahora bien, la clave para establecer aquello que demuestra el razonamiento retórico es doble. Por una parte, Aristóteles analiza la estructura del argumento retórico (silogismo retórico o entimema) y nos muestra que sus premisas son "nociones comunes”, o sea, opiniones (dóxai), que son sustentadas o por todos los hombres, o por una gran mayoría, o por todos los sabios o una parte importante de los mismos. O sea, son nociones compartidas por la comunidad. Estos endoxa, constituyen la plataforma de despegue del argumento retórico.

Ahora bien, el contenido de las opiniones (dóxai) se diferencia netamente del contenido de los conceptos científicos, pues las primeras son verosímiles y los segundos verdaderos. Por esta razón, el entimema es un silogismo conjetural y no apodíctico, como el científico. Pero, y aquí hace su comparecencia la segunda razón, resulta que, según Aristóteles, el hombre recurre a la misma facultad (dunamis) racional para operar ambos tipos de razonamiento. De ahí la conclusión que sigue: “ya que por igual los hombres son suficientemente capaces de verdad y alcanzan por la mayor parte la verdad; por eso tener hábito de conjeturar frente a lo verosímil es propio del que también está con el mismo hábito respecto de la verdad”55.

Así, el razonamiento retórico parte de premisas conocidas por el común de la gente, bajo la forma de dóxai, opiniones, y discurre al hilo de un hábito (héxis) intelectual que consiste en conjeturar sobre cosas verosímiles. Obviamente este modo del razonamiento se mueve dentro de límites, que ya se han establecido. No conjetura sobre cosas eternas y universales,

${ }^{55}$ Reth., 1355 a 15-19. 
ni acerca de lo imposible, sino sobre cosas posibles que se les presentan a los que dialogan como "similares" a las cosas verdaderas. Ahora bien, Aristóteles sobre esta base nos da una segunda definición de la retórica y afirma que ella es una "facultad (dúnamis) para considerar en cada caso lo que cabe para persuadir"56. De este modo, agrega el filósofo, "la retórica sobre cualquier cosa dada, por así decirlo, parece que es capaz de considerar los medios persuasivos" 57 . Así, en el seno de las instituciones que deliberan, la posesión del arte de la retórica pone a disposición del orador el modo argumental que mejor ordena medios persuasivos para inclinar la balanza a una alternativa u opción frente a otra.

Aristóteles distingue en la práctica de la oratoria al que habla (orador), el contenido del discurso y al que escucha. La perspectiva del auditor u oyente es capital, porque a él le corresponde ser persuadido, para conseguir tal o cual decisión. En efecto, es el oyente quien "juzga y es árbitro”, pues al deliberar se propone ejercer su función de último decisor. A este respecto, Aristóteles distingue tres formas retóricas, tomando como eje el tiempo de las cosas que se tratan en la discusión. De este modo, si se juzgan las cosas pasadas, nos instalamos en el dominio de la retórica judicial. Es aquella que se practica en los tribunales de justicia, ante el juez o el jurado, pues todos los argumentos que se exponen en este tipo de foro se refieren a hechos ya acontecidos. En cambio, si se trata de asuntos futuros, hablamos de la retórica deliberativa. Ésta es propiamente política, porque ella no es sino la tecnificación de la deliberación sobre los medios que han de aplicarse para conseguir un efecto futuro de bien público. También, dice Aristóteles, existe una retórica del tiempo presente, que es aquella que practicamos cuando, por ejemplo, hacemos el elogio o el denuesto de una persona o una situación actual ${ }^{58}$.

Los argumentos expuestos tienen a la vista la respuesta a la pregunta por el fin del discurso retórico, que ahora podemos precisar como pregunta por el fin de la retórica deliberativa, que en definitiva no es sino la finalidad de la deliberación misma. Cuando la Asamblea delibera y los oradores argumentan a favor o en contra de tales o cuales propuestas, desean persuadir o disuadir a los espectadores sobre la "conveniencia" o "utilidad" del medio que ellos han escogido para realizar algún fin de la ciudad, y, en última instancia, el bien vivir de la ciudad, que es su fin supremo. El orador deliberativo, dice Aristóteles, tiene por fin lo "útil y lo dañoso", pues "el que persuade aconseja en cuanto le parece mejor, y el que disuade en

\footnotetext{
${ }^{56}$ Reth., 1356 b 25.

${ }^{57}$ Reth., 1356 b 32-33.

${ }^{58}$ Reth., 1358 a 35-40 b 1-8.
} 
cuanto le parece peor”. Y puntualiza que todos los demás elementos de su discurso son accesorios: "todo lo demás lo añaden sobre esto como acce-

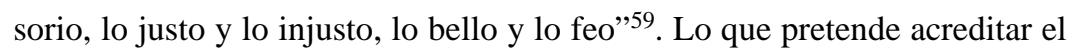
orador deliberativo, a través de esta “especie de demostración” propia del razonamiento retórico deliberativo, es la utilidad del medio que debe elegirse para realizar un fin.

Hay que decir, para finalizar, que la co-deliberación de las instituciones democráticas no exige que todos los que en ella participen dominen el arte de la retórica deliberativa. En realidad, los que dirigen su palabra al auditorio son una minoría. Es la mayoría la que le exige a esa minoría, como auditorio, el ser persuadida o disuadida sobre la utilidad o daño de tal o cual propuesta. Y, desde la perspectiva del orador, lo que sostiene Aristóteles es que la retórica es indispensable para la persuasión. Pero, en definitiva, la retórica supone una democracia a nivel epistémico, porque lo requerido para deliberar es estar informado sobre nociones comunes vigentes en la sociedad. El resto lo hace el sentido común.

\section{Conclusión}

El nómos democrático, la politeia o constitución democrática, les adjudica a los hombres libres poder político. Y ésa es la función de la justicia política que contiene la ley constitucional. En tiempos de la democracia ateniense ese poder se ejercía principalmente en la Asamblea, con la participación directa de los ciudadanos en los procesos de deliberación y decisión política. En las instituciones de participación limitada (Boulé o Consejo de los Quinientos, cuerpo de legisladores, jueces, jurados, etc.), sus miembros son elegidos por sorteo y tienen un período de ejercicio de la autoridad muy limitado, con poderosos efectos de alternancia e igualdad de oportunidades. Todas las autoridades son sometidas a un doble proceso de control: al inicio y al término de las funciones públicas, para exigirles cuentas de su gestión. Todo esto, ciertamente, nos invita a reflexionar sobre la actualidad del pensamiento político de Aristóteles, porque muchas demandas de la democracia deliberativa están presentes en su teoría política: el gobierno por la discusión, el debate público, el control de la actividad gubernativa, la rendición de cuentas de los agentes públicos y los derechos de las minorías a volver sobre las decisiones legislativas. Sobre este último punto, que forma parte del alegato de los partidarios de la democracia deliberativa contemporánea, las sunset laws (leyes con plazos fijos de vigencia, con ocaso

${ }^{59}$ Reth., 1358 b 22-25. 
previsto, para volver a discutir sus contenidos) están en línea con el concepto de la naturaleza contingente de los medios que se eligen para llevar adelante un fin superior del Estado. Y, por otra parte, con la aspiración de los pueblos a que su nómos fundamental, la constitución, sea una ley básica, breve e intangible y cuyos principios de justicia distributiva aseguren la reciprocidad y la cooperación a través de las generaciones.

Nota: En este texto no se discuten los argumentos de Aristóteles contrastando distintas interpretaciones, acerca de las cuales existe una vasta bibliografía. Por esta razón esa bibliografía se omite. Si algún lector se interesa por ella, le ruego comunicarse conmigo vía internet: ogodoy@puc.cl/

\section{Abreviaciones}

Ath. Constitución de Atenas.

Eth. Nic. Ética Nicomaquea.

Phys. Física.

Pol. Política.

Reth. Retórica.

Top. Tópicos.

\section{BIBLIOGRAFÍA}

Aristote: Constitution d'Athènes. París: Societé d’Édition Les Belles Lettres, 1967.

Aristóteles: Ética Nicomaquea. Universidad Autónoma de México, 1954.

Aristote, L'Étique a Nicomaque. París: Publications Universitaires de Louvain, Louvain/Ëditions Béatrice-Nauwelaerts, 1958, Vol. III.

Aristotle: The Nichomachean Ethica. Oxford at the Clarendon Press, 1951.

Aristote: Physique. París: Societé d’Édition Les Belles Lettres, 1967.

Aristóteles: Política. Madrid: Instituto de Estudios Públicos, 1951.

Aristotle: Politics. Books I and II. Oxford: Clarendon Press, 1995.

Aristotle: Politics. Books III and IV. Oxford: Clarendon Press, 1995.

Aristotle: Politics. Books, V and VI. Oxford: Clarendon Press, 1999.

Aristóteles: Retórica. Madrid: Centro de Estudios Políticos y Constitucionales, 199.

Aristotle: The Rethoric of Aristotle. Oxford University Press, 1877.

Aristote: Organon. Les Toxiques. Paris: Livrairie Philosophique J. Vrin, 1950.

Rawls, John: Political Liberalism. Nueva York: Columbia University Press, 1993. 